\title{
Jejunal Absorption and Secretion of Calcium in Patients with Chronic Renal Disease on Hemodialysis
}

\author{
Tom F. Parker, Pedro Vergne-Marini, Alan R. Hull, \\ C. Y. C. PaK, and John S. Fordtran \\ From the Gastroenterology, Renal, and Mineral Metabolism Sections of the \\ Department of Internal Medicine, The University of Texas Southwestern \\ Medical School at Dallas, Dallas, Texas 75235
}

A B S T R A C T 10 patients with chronic renal disease on hemodialysis and 8 normals were studied by constant jejunal perfusion of calcium gluconate solutions, using polyethylene glycol as a nonabsorbable marker. Results in normals indicated that calcium absorption from 1 and $5 \mathrm{mM}$ calcium solutions is mainly active. Absorption from 5,15 , and $20 \mathrm{mM}$ solutions was a linear function of luminal calcium concentration, suggesting that the active transport carrier is saturated when luminal calcium concentration is greater than $5 \mathrm{mM}$ and indicating that the increment in absorption at higher luminal concentrations is mainly the result of passive absorption. With $1 \mathrm{mM}$ calcium, normals absorbed calcium against a concentration gradient, whereas the patients secreted calcium. Absorption in the patients was much less than normal with 5,15 , and $20 \mathrm{mM}$ luminal calcium concentrations; however, the slope of this linear (passive) portion of the curve was normal. Unidirectional calcium fluxes were measured with calcium-47. Flux out of the lumen was depressed 2.5 -fold in the patients, but flux into the lumen was normal. Xylose, urea, and tritiated water were absorbed normally, indicating no generalized abnormality of jejunal transport in these patients. Endogenous calcium secretion, estimated by the amount of calcium added to a calcium-free solution, was normal in the dialysis patients. These results indicate that active calcium absorption is markedly depressed in patients with chronic renal disease who are receiving hemodialysis therapy. On the other hand, passive calcium movement and endogenous calcium secretions are normal.

\section{INTRODUCTION}

Previous studies have established that patients with chronic renal disease are usually in negative calcium

Received for publication 1 February 1974 and in revised form 25 March 1974. balance when they ingest normal or less than normal amounts of calcium in their diet $(1,2)$. This defect may contribute to the development of renal osteodystrophy, and it presumably persists in patients undergoing chronic hemodialysis (3). A variety of methods for estimating radioactive calcium absorption have indicated that at least part of this abnormality is reduced calcium absorption by the intestine (4).

Our paper describes jejunal absorption of calcium, measured by a constant perfusion technique, in 10 patients with end-stage renal disease receiving chronic hemodialysis and in 8 normal subjects. The following were measured: $(a)$ the net rate of calcium absorption with different intraluminal calcium concentrations, $(b)$ the rate of jejunal net secretion of calcium during perfusion of a calcium-free solution, and $(c)$ the unidirectional rates of calcium flux using calcium- 47 .

\section{METHODS}

Patients and controls. 10 patients with end-stage renal disease undergoing hemodialysis three times a week were studied. Eight had chronic glomerulonephritis, one had phenacetin nephritis, and one had nephrocalcinosis. The calcium concentration of the dialysis fluid was $2.5 \mathrm{meq} /$ liter. Eight completely normal people with a similar age and sex distribution were studied for comparison. Pertinent clinical data on the patients and normal people are given in Table I. The patients and the normal subjects gave informed consent for the performance of these studies.

Intestinal perfusion. Subjects were intubated with a triple-lumen polyvinyl tube as previously described (5-7). Intestinal perfusion was begun when the infusion aperture was at the ligament of Treitz, after an 8-h fast and from 12 to $32 \mathrm{~h}$ after completion of dialysis. Intestinal contents were collected at two distal collecting points located 10 and $40 \mathrm{~cm}$ beyond the infusion site. Sampling from the distal collection site was started and stopped $10 \mathrm{~min}$ after the corresponding collection from the proximal site, based on volume flow relationships previously reported (8). Test solutions contained $0.5 \%$ polyethylene glycol as a nonabsorbable volume marker, were prewarmed to $37^{\circ} \mathrm{C}$, bubbled with $\mathrm{CO}_{2}$, and were infused at a constant rate of 
TABLE I

Clinical Inata

\begin{tabular}{lcc}
\hline & Dialysis patients & Normal subjects \\
\hline Age & $46.3 \pm 2.3(31-53)$ & $45.7 \pm 4.2(28-67)$ \\
Duration on dialysis, $m o$ & $16.4 \pm 3.5(4-32)$ & - \\
Known duration of uremia, $m o$ & $19.7 \pm 3.7(5-34)$ & - \\
Calcium intake, ${ }^{*} m g /$ day & $678 \pm 53(350-1,000)$ & $1,053 \pm 82(500-2,300)$ \\
Serum calcium, $m g / 100 m l$ & $8.98 \pm 0.3(7.80-9.70)$ & $9.47 \pm 0.1(8.85-10.0)$ \\
Serum phosphorous, $m g / 100 m l$ & $5.2 \pm 0.4(3.6-7.8)$ & $3.1 \pm 0.4(2.1-5.6)$ \\
Serum sodium, $m e q /$ liter & $137 \pm 0.1(135-140)$ & $140 \pm 1.3(135-148)$ \\
Serum potassium, $m e q / l i t e r$ & $4.4 \pm 0.3(3.7-6.1)$ & $4.4 \pm 0.1(3.8-4.9)$ \\
Serum albumin, $g / 100 m l$ & $3.8 \pm 0.1(3.3-4.5)$ & - \\
Alkaline phosphatase, $m U / m l \ddagger$ & $209 \pm 47(95-680)$ & - \\
BUN, $m g / 100 m l$ & $85 \pm 4(61-112)$ & - \\
Creatinine, $m g / 100 m l$ & $15 \pm 0.7(11-20.4)$ & - \\
\hline
\end{tabular}

Range, Mean \pm 1 SEM.

* Estimated by dietary survey.

$\ddagger$ Normal range $25-95$.

$11 \mathrm{ml} / \mathrm{min}$ with a Holter pump (The Holter Company, Mt. Laurel Township, N. J.). The rate of sampling from the proximal and distal ends of the $30-\mathrm{cm}$ test segment was $1.5 \mathrm{ml} / \mathrm{min}$. Collections were made anaerobically in 30 -ml plastic syringes.

Four test solutions were infused in each subject in random sequence. A given solution was perfused for $1 \frac{3}{2}, \frac{3}{4} \mathrm{~h}$ for equilibration, followed by a 1-h collection period.

Test solutions. Makeup of the test solutions was designed to minimize intestinal absorption or secretion of sodium chloride and water. This was necessary because of the large volume of fluid (approximately 5 liters) infused into the jejunum over the 7-h period, which if absorbed might produce hazardous overload in patients with no renal function. Preliminary studies showed that net water movement in the jejunal test segment was near zero when the infused test solution had a sodium and chloride concentration of $50 \mathrm{meq} / \mathrm{liter}$ and with mannitol added in amounts required to bring the osmolality of the test solution to $200 \mathrm{mosmol} / \mathrm{kg}$. This solution has an effective osmotic pressure in the human jejunum approximately equal to that of plasma (9) ; therefore, its infusion elicits minimal absorption or secretion of water.

The makeup of each solution is shown in Table II. Half of the patients and half of the normal subjects received solution IA, while the other half received IB. All subjects received solutions II, III, and IV, which contained increasing concentrations of calcium gluconate and varying amounts of mannitol. The assumption has been made that any effects of mannitol (and other components of the infusate) on calcium absorption are the same in normals as in the patients. In addition to the ingredients shown in Table II, solutions IA and IB contained $10 \mathrm{mM}$ D-xylose. Radioactive calcium $\left({ }^{47} \mathrm{Ca}\right)$ was added to solution II in 6 of the 8 control subjects and in 6 of the 10 patients. In the 4 patients who did not have ${ }^{47} \mathrm{Ca}$ in solution II, $0.5 \mu \mathrm{Ci} /$ liter of $\left[{ }^{14} \mathrm{C}\right]$ urea ( $1 \mathrm{mM}$ urea carrier) and $5 \mu \mathrm{Ci} /$ liter of tritiated water were added to solutions IA or IB. $\left.{ }^{14} \mathrm{C}\right]$ Urea and tritiated water were not added to the test solutions of the control subjects since normal absorption rates of these substances by this technique have been previously measured (10).
Blood samples. A blood sample was obtained before and at the end of the four perfusions in each subject. Serum was analyzed for calcium, phosphorous, creatinine, blood urea nitrogen (BUN), albumin, and electrolyte concentrations; hemoglobin concentration was also measured.

Analysis of samples. Intestinal samples were analyzed for $\mathrm{pH}$, electrolyte concentration, and polyethylene glycol concentration according to methods that have been previously published $(5,9,10)$. Calcium concentration was analyzed in triplicate by atomic absorption spectrometry (11). Intestinal samples containing ${ }^{47} \mathrm{Ca}$ were counted on a Packard Auto-Gamma spectrometer (model 3348, Packard Instrument Co., Inc., Downers Grove, Ill.). Intestinal samples containing ${ }^{14} \mathrm{C}$ and tritium were counted in an automatic Packard Tri-Carb liquid scintillation spectrometer (model 2425). Phosphorous, alkaline phosphatase, albumin, and hemoglobin concentrations in serum or blood were determined by routine methods.

Calculations. Absorption or secretion rates of calcium, water, and electrolytes were calculated from the perfusion rate, the change in polyethylene glycol concentration and the change in the concentration of the respective solute (5-7). Results are expressed as the mean \pm 1 SE. To represent conditions within the test segment as closely as possible, the calcium concentrations of the perfusate are expressed as the arithmetic mean of the concentration determined at the proximal and distal collection sites. Unidirectional flux of calcium was calculated by the method of Berger and Steele (12).

TABLE II

Test Solutions

\begin{tabular}{lrrrrr}
\hline & IA & IB & II & III & IV \\
\hline $\mathrm{NaCl}, m M$ & 50 & 50 & 50 & 50 & 50 \\
$\mathrm{KCl}, m M$ & 5 & 5 & 5 & 5 & 5 \\
Mannitol, $m M$ & 75 & 75 & 75 & 55 & 40 \\
Ca gluconate, $m M$ & 0 & 1 & 5 & 15 & 20 \\
\hline
\end{tabular}


TABLE III

Water and Sodium Movement and Ion Concentrations in 30-cm Jejunal Test Segment

\begin{tabular}{lcccccc}
\hline & $\Delta \mathrm{H}_{2} \mathrm{O}$ & $\begin{array}{c}\mathrm{Mean} \\
{\left[\mathrm{Na}^{+}\right]}\end{array}$ & $\Delta \mathrm{Na}^{+}$ & $\begin{array}{c}\text { Final } \\
{\left[\mathrm{K}^{+}\right]}\end{array}$ & $\begin{array}{c}\text { Estimated } \\
\mathrm{PD}\end{array}$ & $\begin{array}{c}\mathrm{Mean} \\
\mathrm{pH}\end{array}$ \\
\hline & $m l / h / 30 \mathrm{~cm}$ & meq/liter & meq/h/30 cm & meq/liter & $m \mathrm{mV}$ & \\
Normals & $+41 \pm 7$ & $87.5 \pm 0.8$ & $+13.5 \pm 0.7$ & $4.57 \pm 0.08$ & $1.0 \pm 1.0$ & $6.12 \pm 0.03$ \\
Hemodialysis patients & $+31 \pm 6$ & $81.0 \pm 1.0$ & $+12.5 \pm 0.6$ & $4.84 \pm 0.16$ & $2.9 \pm 1.0$ & $6.26 \pm 0.08$ \\
$P=$ & 0.25 & $<0.001$ & 0.25 & 0.05 & 0.2 & 0.05 \\
\hline
\end{tabular}

$t=$ secretion.

\section{RESULTS}

Water and electrolyte movement. In accord with the design of the test solutions, net water movement was near zero in the $30-\mathrm{cm}$ jejunal test segment (Table III). The slight secretion noted in both groups amounted to only about $5 \%$ of the volume of the test solution infused in $1 \mathrm{~h}$. Although the infused test solution had a sodium concentration of $50 \mathrm{meq} / \mathrm{liter}$, sodium diffused from plasma into the jejunal lumen as the test solution traveled from the infusion site to the proximal end of the test segment. The mean sodium concentration in the test segment was $81.0 \mathrm{meq} / \mathrm{liter}$ in the dialysis patients and $87.5 \mathrm{meq} / \mathrm{liter}$ in the normals. Although this difference is statistically significant, it is not believed to be of sufficient magnitude to affect the absorption rate of any other substance, and especially not of calcium, since calcium absorption is not dependent on luminal sodium concentration $(13,14)$. The reason for the the slightly lower mean sodium concentration in the jejunal lumen of the dialysis patients may be due in part to the development of mild hyponatremia (133 meq/ liter) during the course of this experiment.

Assuming that potassium equilibrates passively across jejunal mucosa (15), the potential difference (PD) between lumen and blood can be calculated from the potassium concentration in fluid collected from the distal sampling site and serum potassium concentration, using the Nernst equation (16). PD estimated in this

TABLE IV

Absorption of $\mathrm{D}-X y l o s e,\left[{ }^{14} \mathrm{C}\right]$ Urea, and Tritiated Water

\begin{tabular}{lccc}
\hline & \multicolumn{3}{c}{ Percent absorption } \\
\cline { 2 - 4 } & D-Xylose & $\left.{ }^{14} \mathrm{C}\right]$ Urea & THO* \\
\hline $\begin{array}{l}\text { Normals } \\
\begin{array}{c}\text { Hemodialysis } \\
\text { patients }\end{array}\end{array}$ & $27.3 \pm 2.7$ & $52.2 \pm 2.6 \ddagger$ & $60.1 \pm 2.6 \ddagger$ \\
\hline
\end{tabular}

* THO, tritiated water.

$\ddagger$ These normal values were reported by us (10) from previous studies using an identical perfusion technique. manner was not significantly different in the two groups (Table III). In both the dialysis patients and in the controls, jejunal PD was near zero, in agreement with previous direct measurements across this segment of the small intestine $(5,16,17)$. These results suggest that any differences in calcium absorption between normals and dialysis patients cannot be attributed to abnormal electrical gradients.

The mean $\mathrm{pH}$ of luminal fluid was 6.26 in the dialysis patients and 6.12 in the normals $(P=0.05)$. This difference could be due to greater secretion of bicarbonate (down the concentration gradient between blood and lumen) in the dialysis patients or to a higher lumen $\mathrm{PCO}_{2}$ in the normals. This slight difference would not be expected to affect the solubility of calcium salts in the jejunal lumen ${ }^{1}$ and therefore probably would have no effect on the rate of jejunal calcium absorption.

Data from the perfusion of the four different test solutions were also analyzed separately; there was no effect of increasing luminal calcium concentration from 0 to $20 \mathrm{mM}$ on jejunal electrolyte or water movement, on the concentration of electrolytes in the test segment, on estimated $\mathrm{PD}$, or on luminal $\mathrm{pH}$.

Weight, serum electrolyte, and mineral concentration changes during the experiment. These dialysis patients gain an average of $1.8 \pm 0.4 \mathrm{~kg}$ weight in between two dialysis periods when they are not taking part in intestinal perfusion experiments. When intestinal perfusion was carried out, their corresponding weight gain was slightly less, $1.2 \pm 0.2 \mathrm{~kg}$. Thus, there is no evidence that our experimental procedure caused an unusual or abnormal volume overload in these patients.

The serum calcium concentration increased from 9.47 to $9.85 \mathrm{mg} / 100 \mathrm{ml}$ in the normal subjects $(P<0.01)$ and fell from 8.98 to $8.83 \mathrm{mg} / 100 \mathrm{ml}$ in the patients $(P>0.4)$. The serum phosphorous and albumin concentration did not change significantly in either group.

${ }^{1}$ Samples of intestinal contents containing $5 \mathrm{mM}$ calcium gluconate do not precipitate in $24 \mathrm{~h}$ at $\mathrm{pH}$ less than 7.4. There is $3 \%$ precipitation at $\mathrm{pH} 8.0,20 \%$ at $\mathrm{pH} 8.5$, and $75 \%$ at $\mathrm{pH} 8.7$. (This is unpublished data from the authors' laboratory.) 


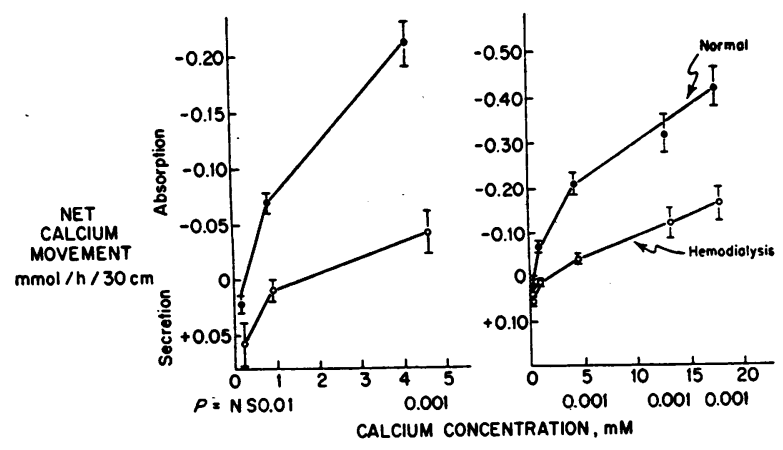

FIgURE 1 Net absorption and secretion rates of calcium during perfusion of $0,1,5,15$, and $20 \mathrm{mM}$ calcium gluconate solutions. Concentrations of calcium are the average of the calcium concentration in fluid aspirated from the proximal and distal ends of the $30-\mathrm{cm}$ jejunal test segment. The left side of the figure is plotted to emphasize the events which occur with low luminal calcium concentrations. All the data are shown on the right side of the figure.

$\mathrm{D}-X y l o s e$, tritiated water, and $\left[{ }^{14} \mathrm{C}\right]$ urea absorption rates. As shown in Table IV, the rate of xylose absorption was the same in normals as in dialysis patients. Also, the rate of tritiated water and $\left[{ }^{14} \mathrm{C}\right]$ urea absorption in the dialysis patients was the same as in a group of normal subjects that we have previously studied by an identical method (10).

Perfusion of a calcium-free solution. During infusion of a calcium-free solution, fluid aspirated $10 \mathrm{~cm}$ distally contained $0.14 \pm 0.05$ and $0.16 \pm 0.03 \mathrm{mM}$ calcium in the normal and dialysis subjects, respectively $(P>0.4)$. When corrected for dilution (by means of the change in concentration of the nonabsorbable marker, polyethylene glycol), the total amount of calcium passing the proximal collecting site was estimated to be $0.10 \pm 0.03 \mathrm{mmol} /$ $\mathrm{h}$ in normals and $0.11 \pm 0.02 \mathrm{mmol} / \mathrm{h}$ in the dialysis patients $(P=0.5)$.

By the time the test solution reached the distal collecting site, $40 \mathrm{~cm}$ from the infusion, calcium concentration was $0.17 \pm 0.05 \mathrm{mM}$ in the normals and $0.25 \pm 0.05$ $\mathrm{mM}$ in the dialysis patients $(P=0.3)$. The mean rate of calcium secretion within the $30-\mathrm{cm}$ jejunal test segment was $0.02 \pm 0.01 \mathrm{mmol} / \mathrm{h} / 30 \mathrm{~cm}$ in the normals and $0.06 \pm 0.02$ in the patients $(P=0.1)$.

Calcium absorption or secretion from 1, 5, 15, and 20 $m M$ calcium gluconate solutions. As shown in Fig. 1, calcium was absorbed at a rate of $0.07 \mathrm{mmol} / \mathrm{h} / 30 \mathrm{~cm}$ in normal subjects when the infusion solution contained $1 \mathrm{mM}$ calcium gluconate. (The secretion rate in response to calcium-free perfusion is included for comparison.) Since the normal serum ionized and diffusible calcium concentrations are 1.2 and $1.5 \mathrm{mM}$, respectively (18), these results demonstrate that normal subjects absorb calcium against a concentration gradient. Ionized and diffusible calcium concentration in the blood of patients with renal disease is probably lower than normal, and absorption by passive mechanisms should therefore be higher (at any given luminal calcium concentration) than normal in these patients, other factors being equal. However, these patients secreted rather than absorbed calcium when the lumen calcium concentration was $1 \mathrm{mM}$. Thus, our results provide no evidence that dialysis patients are able to absorb calcium against $\bar{c}$ concentration gradient.

Fig. 1 also shows the calcium absorption rates in the normal and hemodialysis subjects during jejunal perfusion with 5,15 , and $20 \mathrm{mM}$ calcium gluconate solutions. Calcium absorption in the normals rose sharply as luminal calcium concentration increased from 1 to 5 $\mathrm{mM}$. Absorption rate then increased more gradually and in an approximately linear fashion as calcium concentration increased from 5 to $17 \mathrm{mM}$, reaching a maximum of $0.42 \mathrm{mmol} / \mathrm{h} / 30 \mathrm{~cm}$. The hemodialysis patients absorbed calcium at a much slower rate at all luminal calcium concentrations, reaching a maximum of only 0.17 $\mathrm{mmol} / \mathrm{h} / 30 \mathrm{~cm}$. There was no sharp rise in the absorption rate between 1 and $5 \mathrm{mM}$ luminal concentration. However, absorption between 5 and $17 \mathrm{mM}$ calcium concentration was linear, with a slope that was not significantly different from normal $(P=0.3$ by statistical test for homogeneity of regression [19]).

Unidirectional calcium flux measured with " $\mathrm{Ca}$. Fig. 2 shows the net calcium absorption rates and the unidirectional calcium fluxes (out of the lumen and into the lumen) when luminal calcium concentration was approximately $5 \mathrm{mM}$. Net absorption and flux out of the lumen were much higher in normals than in dialysis patients; in fact, all normal subjects had higher values than any of the patients. Unidirectional calcium flux
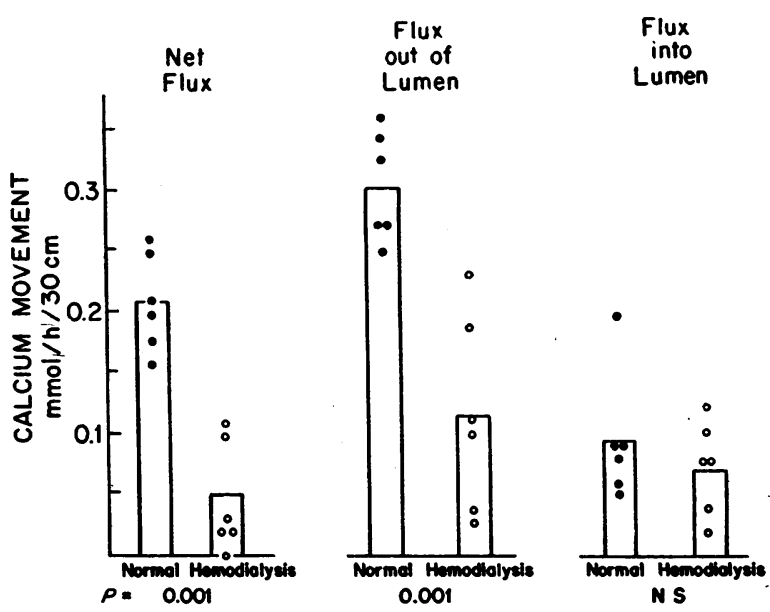

Figure 2 Net and unidirectional calcium flux rates during perfusion of $5 \mathrm{mM}$ calcium gluconate. Unidirectional flux rates were calculated from the absorption rate of radioactive calcium, using the method of Berger and Steele (12). 
TABLE V

Calcium Absorption in Patients with Severe Chronic Renal Disease*

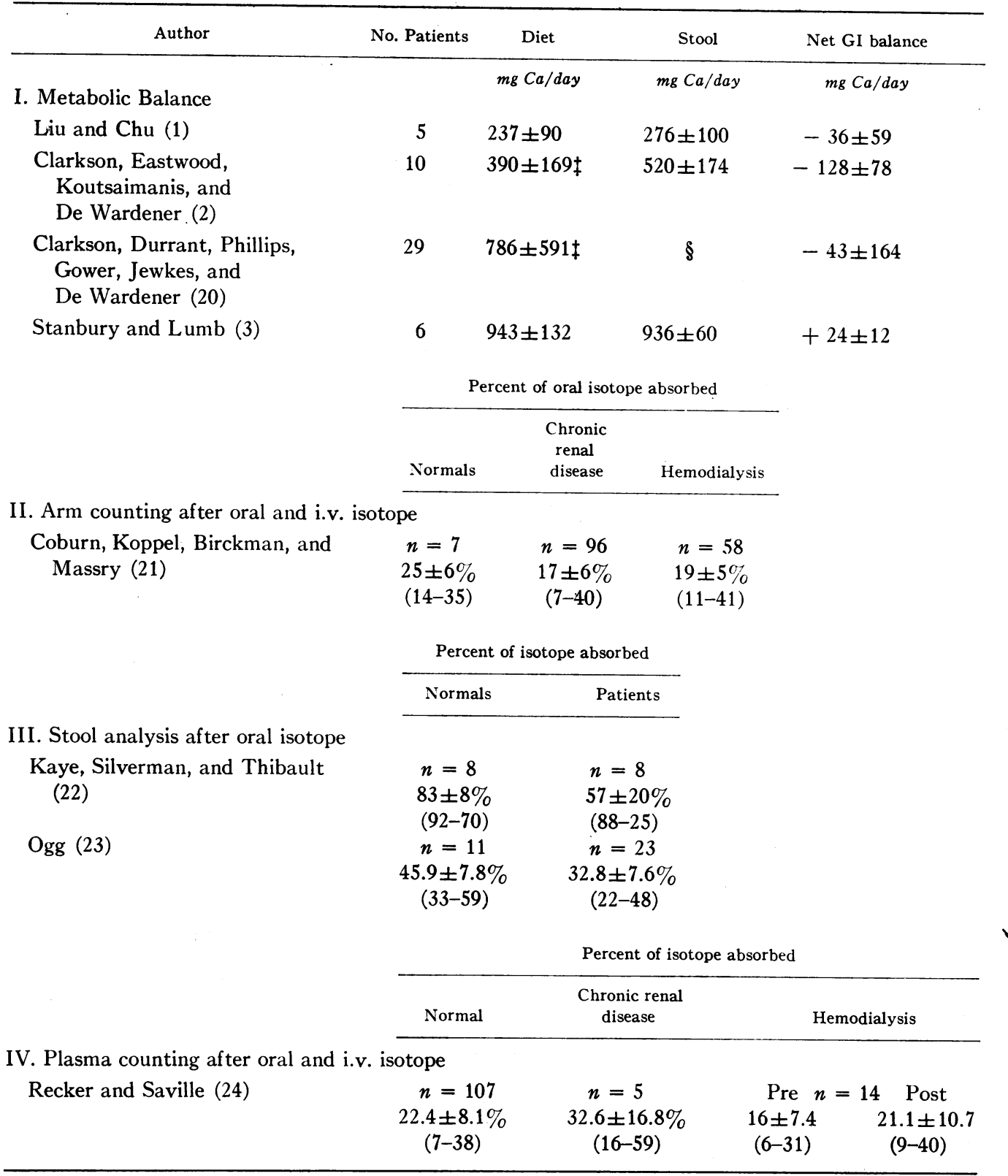

* Mean \pm SD.

$\ddagger$ Data changed from milliequivalents to milligrams.

$\S$ Fecal excretion not reported.

into the lumen was not significantly different in the two groups.

From an analysis of the data in Fig. 2, the unidirectional flux rates which combine to yield the net flux can be obtained. The normal net flux of 0.22 (units omitted) resulted from a flux out of the lumen of 0.31 and a flux into the lumen of 0.09 . In the dialysis patients the net flux of 0.04 resulted from a flux out of the lumen of 0.11 and a flux into the lumen of 0.07 . In the normals the net flux (absorption) was $70 \%$ of the unidirectional flux out of the lumen, whereas in the dialysis patients the net flux was only $40 \%$ of the unidirectional flux out of the lumen.

It was also of interest to compare the unidirectional 
flux into the lumen in Fig. 2 with the net flux into the lumen (secretion) that occurred when the jejunum was perfused with a calcium-free solution. In the normals the flux into the lumen was 0.09 while the net secretion rate (during perfusion of the calcium-free solution) was 0.02 . In the dialysis patients unidirectional flux into the lumen was 0.07 , and the secretion rate was 0.06 . Thus, the normal subjects had a net secretion (in response to a calcium-free solution) of only $22 \%$ of the unidirectional flux into the lumen. In the dialysis patients, on the other hand, the net secretion amounted to $80 \%$ of the unidirectional flux into the lumen.

\section{DISCUSSION}

Some of the previous studies on calcium absorption in patients with chronic renal disease are summarized in Table V. Metabolic measurements have shown that fecal calcium exceeds dietary intake when intake is 237,390 , or $786 \mathrm{mg}$ of calcium per day. Only when intake was increased to $943 \mathrm{mg}$ of calcium per day was there net absorption by the digestive system. In normal subjects, on the other hand, there is net gastrointestinal absorption of calcium even when daily calcium intake is reduced below $250 \mathrm{mg}(25,26)$. These results indicate that the digestive system in patients with chronic renal disease behaves in a grossly abnormal fashion with respect to calcium metabolism. The defect might be due to reduced absorption of calcium by the intestine, to increased secretion by intestinal mucosal cells, or to increased amounts of calcium in biliary, pancreatic, and gastric secretions.

Calcium absorption by the small intestine has been estimated by several methods utilizing radioactive calcium. As shown in Table $\mathrm{V}$, by arm-counting methods and stool analysis after oral isotope ingestion, average radioactive calcium absorption is depressed by $25-30 \%$ in patients with chronic renal disease (including those on chronic hemodialysis). However, there is a great deal of overlap, and some patients have high-normal rates of radioactive calcium absorption. Furthermore, by a plasma counting method Recker and Saville (24) reported higher than normal average rates of radioactive calcium absorption in patients with severe renal insufficiency. Thus, whereas most workers have found some depression of mean radioactive calcium absorption in patients with renal disease, this has not been a uniform observation.

Our studies were performed in $30-\mathrm{cm}$ segments of the proximal jejunum, and they demonstrate a marked and consistent abnormality of calcium absorption in patients with renal disease who are undergoing chronic hemodialysis. For example, their mean rate of calcium absorption was only one-fifth the normal rate when luminal calcium concentration was $5 \mathrm{mM}$, and none of the dialysis patients had an absorption rate within the normal range with $1,5,15$, or $20 \mathrm{mM}$ calcium solutions. Thus, jejunal absorption of calcium is more markedly and consistently reduced in patients with renal disease than is the intestinal absorption of an oral dose of radioactive calcium (Table V). This discrepancy cannot be attributed to the fact that our patients were on dialysis therapy since radioactive calcium absorption is, if anything, less depressed in hemodialysis patients than in others with severe renal insufficiency (21).

There are three main reasons why an oral dose of radioactive calcium might be absorbed normally or be only modestly reduced, whereas net jejunal calcium absorption is markedly depressed. First, net calcium absorption in the jejunum is more markedly reduced in dialysis patients than is radioactive calcium absorption (expressed as flux out of the lumen), i.e. with perfusion of $5 \mathrm{mM}$ calcium net absorption was reduced fivefold, whereas radioactive calcium absorption was reduced by a factor of 2.5 (Fig. 2). Therefore, the rate of radioactive calcium absorption may underestimate the extent of net calcium malabsorption. Second, it is possible that ileal hyperabsorption may compensate for severe calcium malabsorption in the proximal small intestine. This has been suggested by Brickman, Coburn, Rowe, Massry, and Koppel (27), on the basis of a timed arm-counting method after ingestion of radioactive calcium. Finally, absorption of orally ingested radioactive calcium could be normal even though net calcium absorption throughout the intestine is severely depressed. This could occur, for example, by a slow molecular exchange of radioactive calcium in the gut lumen with body calcium, perhaps during the slow transit of material through the colon. Additional work is required to settle this important question of the extent to which net calcium absorption throughout the entire length of the intestine is reduced in patients with chronic renal insufficiency.

Analysis of these perfusion experiments may provide more insight into the mechanism of abnormal calcium absorption than has previously been available from the use of other methods. First of all, this defect is not the result of a nonspecific intestinal disorder, since the patients absorb xylose, tritiated water, and $\left[{ }^{14} \mathrm{C}\right]$ urea in a normal fashion (Table IV). Second, there are differences in the characteristics of the calcium concentration-absorption data (Fig. 1) in the dialysis patients and in the normal subjects. In normals there was an initial steep rise in absorption rate as luminal concentration was increased from 1 to $5 \mathrm{mM}$; probably this portion of the curve reflects mainly the active component of calcium absorption. Increasing luminal calcium concentration to higher levels was associated with a much smaller increase in the rate of calcium absorption, and absorption from 5, 15, and $20 \mathrm{mM}$ calcium solutions was an approximately linear function of luminal concentration. This suggests that the active transport 
carrier is saturated when luminal calcium concentration is $5 \mathrm{mM}$ and that the increment in absorption at higher concentrations is mainly the result of passive calcium absorption down the existing concentration gradient. In the hemodialysis patients there was no sharp increase in the rate of calcium absorption as luminal calcium increased from 1 to $5 \mathrm{mM}$, and, in contrast to the result in normal subjects, calcium was not absorbed against a concentration gradient when the $1 \mathrm{mM}$ calcium solution was infused. The most reasonable interpretation of these results is that the active component of calcium absorption is markedly depressed in hemodialysis patients. Persistence of some active transport is suggested by the fact that net calcium movement was not a linear function of luminal calcium concentration, i.e., there was a slight "break" in the curve at the lower concentrations of calcium (Fig. 1). Consistent with a depression of active calcium absorption in dialysis patients is their reduced unidirectional flux of calcium out of the lumen (Fig. 2). Passive calcium absorption, on the other hand, appears to be within normal limits in dialysis patients since the slope of the linear portion of the kinetic results (between 5 and $17 \mathrm{mM}$ luminal calcium concentration) was not significantly different from normal (Fig. 1) and since the unidirectional flux of calcium into the lumen was approximately the same in patients as in controls (Fig. 2).

Although the results discussed so far point to a defect in active jejunal calcium absorption in dialysis patients, they do not exclude increased secretion of calcium by the digestive tract as a contributing factor to the overall abnormality in the digestive system handling of calcium. To explore this possibility, we examined the rate at which calcium was added to an infused calcium-free solution as it traveled through the proximal jejunum. Fluid aspirated $10 \mathrm{~cm}$ below the infusion point is a mixture of the infused test solution and endogenous secretions from the upper gastrointestinal tract $(6,7)$. The calcium content of this fluid was the same in dialysis patients as in normals, suggesting that digestive secretions of the patients do not contain excessive amounts of calcium. The net rate of calcium secretion between the proximal and distal sampling sites was also measured to see if the jejunal mucosa secretes an excessive amount of calcium in dialysis patients. Mean net secretion rate (down the concentration gradient) was three times higher in the patients than in the normals, although the $P$ value for this difference was only 0.1 . It seems likely that the higher mean secretion rate in patients is due to less reabsorption of secreted calcium, rather than an indication of increased secretion rate per se, since the unidirectional flux of calcium into the lumen is not increased in the dialysis patients (Fig. 2). It is interesting that the net secretion of calcium during infusion of a calcium-free solution amounted to only $22 \%$ of the unidirectional flux of calcium into the lumen in normals, whereas in the dialysis patients, the net secretion amounted to $80 \%$ of the unidirectional flux into the lumen. This supports the notion that there is very little reabsorption of secreted calcium in the dialysis patients at low intraluminal calcium concentrations, compared to normals where a high fraction of secreted calcium is reabsorbed. Thus, the increased net calcium secretion in dialysis patients during perfusion of a calcium-free solution is probably due to the same abnormality which depresses the absorption rate of calcium at higher luminal calcium concentrations, i.e., the marked depression of active calcium absorption.

Recent studies have indicated that abnormalities in calcium homeostasis in uremic patients are mainly due to vitamin $\mathrm{D}$ deficiency which develops because of the inability of diseased kidneys to synthesize 1,25-dihydroxycholecalciferol, the most active vitamin $\mathrm{D}$ metabolite $(28,29)$. It is of interest, therefore, to compare our findings in hemodialysis patients with end-stage renal disease with the work of others in laboratory animals made vitamin $\mathrm{D}$ deficient by dietary deprivation. Our findings of reduced active calcium transport, decreased net calcium absorption at all levels of intraluminal calcium concentration, and decreased unidirectional flux of calcium out of the lumen are in agreement with observations of many others who have made similar measurements in vitro and in vivo in vitamin D-deficient animals. On the other hand, the normal unidirectional flux of calcium into the lumen in our patients does not agree with the findings of others in vitamin D-deficient animals. For example, Wasserman and Kallfelz (30) found this flux to be markedly reduced in rachitic chickens in vivo, whereas Favus, Walling, and Kimberg (31) found this flux increased almost twofold in vitamin Ddeficient rats in vitro. These conflicting results are presumably due to species and/or technical differences. In addition, of course, the calcium transport defect in humans with chronic renal disease may be due to more than vitamin $\mathrm{D}$ deficiency.

\section{ACKNOWLEDGMENTS}

This work was supported by research grant 5 RO1 AM 06506 from the National Institute of Arthritis and Metabolic Diseases and by General Clinical Research Centers Program of the Division of Research Resources, National Institutes of Health grant 1-MO1-RR 00633.

\section{REFERENCES}

1. Liu, J. H., and H. I. Chu. 1943. Studies of calcium and phosphorous metabolism with special reference to pathogenesis and effects of dihydrotachysterol and iron. Medicine (Baltimore). 22: 103-161. 
2. Clarkson, E. M., J. B. Eastwood, K. G. Koutsaimanis, and H. E. De Wardener. 1973. Net intestinal absorption of calcium in patients with chronic renal failure. Kidney Int. 3: 258-263.

3. Stanbury, S. W., and G. A. Lumb. 1962. Metabolic studies of renal osteodystrophy. I. Calcium, phosphorous and nitrogen metabolism in rickets, osteomalcia and hyperparathyroidism complicating chronic uremia and in the osteomalaciaci of the adult Fanconi Syndrome. Medicine (Baltimore). $41: 1-34$.

4. Coburn, J. W., D. L. Hartenbower, and S. G. Massry. 1973. Intestinal absorption of calcium and the effect of renal insufficiency. Kidney Int. 4: 96-104.

5. Fordtran, J. S., F. C. Rector, Jr., and N. W. Carter. 1968. The mechanisms of sodium absorption in the human small intestine. J. Clin. Invest. 47: 884-900.

6. Fordtran, J. S. 1966. Marker perfusion techniques for measuring intestinal absorption in man. Gastroenterology. 51: 1089-1093.

7. Fordtran, J. S. 1969. Segmental perfusion techniques. Gastroenterology. 56: 987-989.

8. Dillard, R. L., H. Eastman, and J. S. Fordtran. 1965. Volume-flow relationship during the transport of fluid through the human small intestine. Gastroenterology. 49: $58-66$.

9. Fordtran, J. S., F. C. Rector, Jr., M. F. Ewton, N. Soter, and J. Kinney. 1965. Permeability characteristics of the human small intestine. J. Clin. Invest. 44: 19351944.

10. Fordtran, J. S., F. C. Rector, Jr., T. W. Locklear, and M. F. Ewton. 1967. Water and solute movement in the small intestine of patients with sprue. J. Clin. Invest. $46: 287-298$.

11. Ireland, P., and J. S. Fordtran. 1973. Effect of dietary calcium and age on jejunal calcium absorption in humans studied by intestinal perfusion. J. Clin. Invest. $52: 2672-2681$.

12. Berger, E. Y., and J. M. Steele. 1958. The calculation of transfer rates in two compartment systems not in dynamic equilibrium. J. Gen. Physiol. 41: 1135-1152.

13. Wasserman, R. H., and A. N. Taylor. 1963. The nonessentiality of sodium ions for intestinal calcium transport. Proc. Soc. Exp. Biol. Med. 114: 479-482.

14. Harrison, H. E., and H. C. Harrison. 1963. Sodium, potassium, and intestinal transport of glucose, $l$-tyrosine, phosphate and calcium. Am. J. Physiol. 205: 107-111.

15. Turnberg, L. A. 1971. Potassium transport in the human small bowel. Gut. $12: 811-818$.

16. Bieberdorf, F. A., P. Gorden, and J. S. Fordtran. 1972. Pathogenesis of congenital alkalosis and diarrhea. Implications for the physiology of normal ileal electrolyte absorption and secretion. J. Clin. Invest. 51: 1958-1968.
17. Turnberg, L. A., J. S. Fordtran, N. W. Carter, and F. C. Rector, Jr. 1970. Mechanism of bicarbonate absorption and its relationship to sodium transport in the human jejunum. J. Clin. Invest. 49: 548-556.

18. Moore, E. W. 1970. Ionized calcium in normal serum, ultrafiltrates and whole blood determined by ion-exchange electrodes. J. Clin. Invest. 49: 318-334.

19. Steel, R. G. D., and J. H. Torrie. 1960. Principles and Procedures of Statistics. McGraw-Hill Book Company, New York. 173-174.

20. Clarkson, E. M., C. Durrant, M. E. Phillips, P. E. Gower, R. F. Jewkes, and H. E. De Wardener. 1970 The effect of a high intake of calcium and phosphate in normal subjects and patients with chronic renal failure. Clin. Sci. (Oxf.). 39: 693-704.

21. Coburn, J. W., M. H. Koppel, A. S. Brickman, and S. G. Massry. 1973. Study of intestinal absorption of calcium in patients with renal failure. Kidney Int. 3: 264-272.

22. Kaye, M., M. Silverman, and I. Thibault. 1965. Calcium metabolism in chronic renal failure. J. Lab. Clin. Med. 66: $535-548$.

23. Ogg, C. S. 1968. The intestinal absorption of ${ }^{47} \mathrm{Ca}$ by patients in chronic renal failure. Clin. Sci. (Oxf.). 34: $467-471$.

24. Recker, R. R., and P. D. Saville. 1971. Calcium absorption in renal failure: its relationship to blood urea nitrogen, dietary calcium intake, time on dialysis, and other variables. J. Lab. Clin. Med. 78: 380-388.

25. Heaney, R. P., and T. G. Skillman. 1964. Secretion and excretion of calcium by the human gastrointestinal tract. J. Lab. Clin. Med. 64: 29-41.

26. Hegsted, D. M., I. Moscoso, and C. Collazos Ch. 1952. A study of the minimum calcium requirements of adult men. J. Nutr. 46: 181-201.

27. Brickman, A. S., J. W. Coburn, P. H. Rowe, S. G. Massry, and M. H. Koppel. 1972. Delayed Ca absorption in uremia: evidence for impaired transport in proximal small intestine. Proc. Int. Congr. Nephrol. 5: 459.

28. Leading Article. 1972. Action of 1,25-dihydroxycholecalciferol in uremia. Lancet. 2 : 1185-1186.

29. Brickman, A. S., J. W. Coburn, and A. W. Norman. 1972. Action of 1,25-dihydroxycholecalciferol, a potent, kidney-produced metabolite of vitamin $\mathrm{D}_{3}$, in uremic man. N. Engl. J. Med. 287: 891-895.

30. Wasserman, R. H., and F. A. Kallfelz. 1962. Vitamin $\mathrm{D}_{3}$ and unidirectional calcium fluxes across the rachitic chick duodenum. Am. J. Physiol. 203: 221-224.

31. Favus, M. J., M. W. Walling, and D. V. Kimberg. 1973. Effects of 1,25-dihydroxycholecalciferel on intestinal calcium transport in cortisone-treated ra s. J. Clin. Invest. 52: 1680-1685. 